\title{
Drugs for the Treatment of Chronic Hand Eczema: Successes and Key Challenges
}

This article was published in the following Dove Press journal:

Therapeutics and Clinical Risk Management

\author{
Celina Dubin' \\ Ester Del Duca ${ }^{1,2}$ \\ Emma Guttman-Yassky (D) 1,3 \\ 'Department of Dermatology, \\ Laboratory of Inflammatory Skin \\ Diseases, Icahn School of Medicine at \\ Mount Sinai, New York, NY, USA; \\ ${ }^{2}$ Department of Dermatology, University \\ of Magna Graecia, Catanzaro, Italy; \\ ${ }^{3}$ Laboratory for Investigative \\ Dermatology, The Rockefeller University, \\ New York, NY, USA
}

\begin{abstract}
Chronic hand eczema (CHE) is a common and burdensome inflammatory skin condition seen in up to $10 \%$ of the population, more often in high-risk occupational workers. Topical therapeutics comprise the standard of care, but up to $65 \%$ of cases do not resolve after treatment, and moderate-to-severe cases are often resistant to topical therapeutics and require systemic options instead. To date, there are no systemic therapeutics approved to treat $\mathrm{CHE}$ in the United States, but several drugs are under investigation as potential treatments for CHE. The primary focus of this review is on the novel therapeutics, topical and systemic, that are under investigation in recently completed or currently ongoing trials. This review also briefly outlines the existing treatments utilized for CHE, often with limited success or extensive adverse effects. CHE represents a major challenge for physicians and patients alike, and efforts to improve the minimally invasive diagnostic tools and treatment paradigms are ongoing. In the near future, $\mathrm{CHE}$ patients may benefit from new topical and systemic therapeutics that specifically target abnormally expressed immune markers.
\end{abstract}

Keywords: AFX5931, chronic hand eczema, delgocitinib, dupilumab, gusacitinib, roflumilast

\section{Introduction}

\section{Chronic Hand Eczema Prevalence and Clinical Presentation}

Chronic hand eczema (CHE) is an inflammatory skin condition with a $10 \%$ prevalence in the general population. ${ }^{1-4} \mathrm{CHE}$ is most common in people who work in high risk occupations with consistent water exposure to the hands, including health care workers, hair dressers, cooks, cleaners, and others working in manufacturing involving direct hand work. ${ }^{1,5}$ There is an enormous psychosocial burden of disease and the functional impairment from HE has been identified as a major cause of morbidity and employment-related financial hardships. ${ }^{2,6-8}$ Recent studies reported that up to $82 \%$ of CHE patients had to change their work situation, $48 \%$ had taken sick leave for several days at a time, and at least $15 \%$ were on unemployment or disability pension. ${ }^{2,6-8}$ Further, CHE has an overwhelming impact on quality of life due to repercussions from the pain and itch symptoms for work and social activities, as well as the psychological stress due to visibility of the hands. ${ }^{2,9} \mathrm{CHE}$ is diagnosed in individuals with hand eczema of more than 6 months duration. Clinically, hand eczema is characterized by cutaneous fissures and vesicles in the setting of erythema, often associated with scaling and hyperkeratosis, and symptoms of itch and pain. The morphology can be confused with other skin conditions such as psoriasis, mycosis, and atopic dermatitis, among others. ${ }^{4,9}$
Correspondence: Emma Guttman-Yassky Department of Dermatology, Laboratory of Inflammatory Skin Diseases, Icahn School of Medicine at Mount Sinai, 5 E. 98th Street, New York, NY 10029 USA

Tel $+\mid$ 2| 2-24|-9728

$\mathrm{Fax}+\mid$ 2|2-876-896|

Email Emma.Guttman@mountsinai.org
Therapeutics and Clinical Risk Management 2020:16 1319-1332 DovePress f in $P$ 


\section{CHE Etiologies and Pathogenesis}

CHE is a heterogenous condition, with a wide range of etiologies and clinical manifestations that are in large part due to a multifactorial pathogenesis. Most cases of hand eczema are caused by a combination of etiologies. There are three main etiologic classifications of hand eczema: irritant contact dermatitis (ICD), allergic contact dermatitis (ACD), and atopic hand eczema, which accounts for over $50 \%$ of cases. ${ }^{4,-12}$ ICD is due to prolonged exposure to skin irritants such as detergents, solvents, sweat, and frequent exposure to water, which compromises the skin barrier and causes a contact allergy., ${ }^{4,13,14}$ Atopic hand eczema is a delayed type IV hypersensitivity reaction to a chemical substance, typically nickel, chromate, rubber, or preservatives. This form of hand eczema can be diagnosed with patch testing. ${ }^{4,9,15}$ Atopic hand eczema is the most common etiology of hand eczema, accounting for over $50 \%$ of cases. ${ }^{4,12,16,17}$ Further, atopic dermatitis (AD) is the most important risk factor for chronic hand eczema, and up to one half of patients with CHE have other atopic conditions including asthma, allergic rhinitis, elevated IgEs, and atopic dermatitis. ${ }^{9,18-20}$

The pathogenesis of CHE is dependent upon the primary etiology of the eczema. Each etiology has a unique immune signature that should, ideally, be targeted for effective treatment of the condition. Irritant contact dermatitis has a Th1/Th17 immune profile that results from the activation of IL-1a, IL-1B, TNF-a, GM-CSF, and IL-8 from keratinocytes upon exposure to an irritant. ${ }^{21-23}$ This immune activation causes damage to the keratinocytes, which promotes cellular infiltrate from inflammatory cells such as neutrophils and mast cells. ${ }^{21-23}$ ACD shows a variable immune signature, dependent upon the allergen at play. Metal-induced ACD typically presents with a Th1/ Th17 immune profile, with elevated markers of innate immunity and expression of IL-1B, IL-6, IFN- $\alpha 1$, CXCL1, CXCL2, CXCL9, CXCL10, and CXCL11. ${ }^{15,21,24}$ Fragrance and rubber-induced ACD typically presents with a Th2/Th22 immune profile, inducing cytokines such as IL-5, IL-13, IL-22, IL-32, CCL5, CCL13, CCL17, CCL18, and CTLA4. ${ }^{15,21,24}$ Atopic hand eczema, like other atopic conditions, presents with a Th2/ Th22 immune profile, in conjunction with endogenous factors such as tight junction defects and an increase in transepidermal water loss (TEWL), thereby compromising the integrity of the epidermal barrier. ${ }^{1,25-28}$ Atopic hand eczema lesions are characterized by increased Th2 activation and production of IL-4, IL-13, IL-31, CCL17, CCL18, and CCL22, and T-cell activation that produces IL-22. IL-4/IL-13 also induce increased IgE synthesis, which characterizes many CHE cases. ${ }^{21,22,29}$

\section{CHE Treatment Paradigm}

There is a large unmet need for effective therapeutics for long-term control of CHE, particularly moderate-to-severe cases, as there are currently no FDA-approved treatments for chronic hand eczema. ${ }^{30} \mathrm{Up}$ to $65 \%$ of patients continue to experience recurrent episodes of HE after 5 years of treatment with topicals. ${ }^{1,6}$ Patients with mild to moderate CHE are often treated with hydration, emollients, or high potency topical steroids or calcineurin inhibitors, but these options are often unsatisfactory. ${ }^{1,2,4,31-33} \mathrm{New}$ immunetargeted treatments are being investigated in clinical trials. Topical pan-Janus Kinase (JAK) inhibitor delgocitinib has shown promising data for treating mild-to-severe CHE in a completed Phase 2 trial - it was efficacious and well tolerated, showing clearance of CHE after 8 weeks of treatment compared to placebo. ${ }^{34,35}$ There are also ongoing studies with phosphodiesterase type 4 inhibitors (PDE4) and inhibitors of highly inflammatory chemokines CCL2 and CCL5 for the treatment of mild to moderate CHE. ${ }^{1,35-38}$ These are all important targets that have been found to be dysregulated across CHE etiologies.

Still, moderate-to-severe cases are often refractory to topical treatments. Thus far, alitretinoin is the only systemic therapy approved for the treatment of severe hand eczema, but it is approved only in Europe, Canada, Israel, and South Korea. ${ }^{39-41}$ While no systemic therapies have been approved in the United States, several are being investigated in clinical trials, including existing oral immunosuppressants such as cyclosporine and azathioprine, which have shown some efficacy in treating moderateto-severe CHE, but they are limited by the side effect profile. ${ }^{42-45}$ Other systemic options, including oral JAK/ spleen tyrosine kinase (SYK) inhibitors and injectable biologics, namely gusacitinib, a JAK/SYK inhibitor, and dupilumab, a monoclonal antibody towards IL-4R $\alpha$ that is approved for the treatment of moderate-to-severe atopic dermatitis, are being investigated in clinical trials. A phase 2 trial of gusacitinib in CHE has reported initial promising results, with dose-dependent improvements in hand eczema compared to placebo, and several case and observational studies of Dupilumab have similarly shown significant improvements in moderate-to-severe CHE. ${ }^{46-49}$ Dupilumab specifically targets $\mathrm{Th} 2$ cytokines and has 
a highly favorable safety profile, and gusacitinib targets several cytokine axes that may be involved in CHE, making them potentially promising treatment options, but both are still in early stages of investigation. ${ }^{49-53}$

The heterogeneity of CHE and the lack of approved systemic treatments advocates for a more precise and efficacious approach to long term disease management. This review will focus on novel topical and systemic treatments in a current or recently completed clinical study investigation for chronic hand eczema, with a review of several of the most relevant existing drugs approved for other conditions that have also been investigated through clinical study for CHE (summarized in Table 1). To identify treatments to review in this article, we conducted a thorough search using the United States Clinical Trials database (clinicaltrials.gov) and searched for all trials using the key terms "chronic hand eczema," "hand eczema," and "hand dermatitis." In addition to outlining the successes in treating CHE, this review also highlights the key challenges still faced in CHE drug development and clinical management.

\section{Existing Topical Therapeutics}

Calcipotriol, a topical Vitamin D3 derivate that has been studied for the treatment of several skin diseases, has also been evaluated as a treatment for hand eczema. ${ }^{39,54,55}$ Calcipotriol affects epidermal cells by prohibiting proliferation, angiogenesis, and cytokine production, and regulates hapten-induced immune responses by dendritic cells, ${ }^{1,39,54}$ but its widespread use is limited by common side effects such as skin scaling, dryness, and irritation. ${ }^{55,56}$ Case reports of several patients have shown improvements in hand eczema after treatment with topical calcipotriol, ${ }^{39,54}$ and a recent prospective, randomized trial found that $0.005 \%$ calcipotriol was as effective as topical steroids in improving clinical severity of hand eczema. ${ }^{55}$

Calcineurin inhibitors, another class of existing topicals, are frequently used in the treatment of mild to moderate chronic hand eczema. ${ }^{9,57-59}$ They inhibit the transcription of various inflammatory cytokines released from T-cells and mast cells by affecting the nuclear factor kappa B pathway and blocking calcineurin phosphate activity, and therefore function as potent, but nonspecific, anti-inflammatories. . $^{1,59,60}$ Pimecrolimus, a topical calcineurin inhibitor, has widely been used in the treatment of atopic dermatitis and chronic hand eczema. ${ }^{57,58}$ Three trials have evaluated the efficacy of
$1 \%$ pimecrolimus cream for the treatment of $\mathrm{CHE},{ }^{58,61,62}$ and have found that patients experience significant improvement in clinical severity and symptomatology (Table 1). ${ }^{61,63}$ Tacrolimus, another topical calcineurin inhibitor, has previously been approved to treat atopic dermatitis but has less skin penetration than pimecrolimus. ${ }^{64}$ Though it has been efficacious in improving distressing inflammatory symptoms in patients with $\mathrm{CHE},{ }^{59,65}$ one prospective study found it only achieved complete clearing of disease in $44 \%$ of participants. ${ }^{64}$

Topical steroids, in various formulations, are another class of drugs utilized for the treatment of CHE, as they are effective anti-inflammatory, anti-mitotic, and immunosuppressive medications that are easy to administer. ${ }^{66-68}$ However, topical steroid use is limited by several side effects seen with prolonged use, including tachyphylaxis and dermal atrophy, among others. ${ }^{69,70}$ Topical clobetasol propionate, is an old, high potency corticosteroid that has been utilized in mild to moderate cases of chronic hand eczema. An open-label study of the efficacy of clobetasol propionate $0.05 \%$ foam found improvement in $96.7 \%$ of subjects after 15 days of use, concluding that clobetasol propionate foam is an effective and safe treatment for chronic hand eczema (Table 1). ${ }^{71,72}$ Triamcinolone acetonide is another combination topical steroid investigated for the treatment of $\mathrm{CHE}^{73}$ and it has also been evaluated for the treatment of allergic and irritant contact dermatitis, for which it has shown variable efficacy in reducing clinical severity. ${ }^{74}$ Halometasone is a glucocorticoid recently investigated as a combination formula with antibacterial, triclosan, for the treatment of CHE. ${ }^{75,76}$ This topical serves as an effective combination, functioning as an antiseptic and anti-inflammatory to improve microbial colonization with Staphylococcus aureus (S. aureus) in affected skin as well as inflammation. ${ }^{76,77}$

Though there has been modest success in the treatment of CHE with existing topical drugs, their use is limited to mild-to-moderate cases and long-term they are associated with several side effects. This has advocated for the development of novel treatments that are efficacious and well tolerated across the spectrum of clinical severity.

\section{Novel Topical Therapeutics Small Molecule Drugs}

Small molecule drugs are a new class of treatments that have previously been shown to be effective therapeutics for atopic dermatitis. ${ }^{78-81}$ Due to their small size, they can 


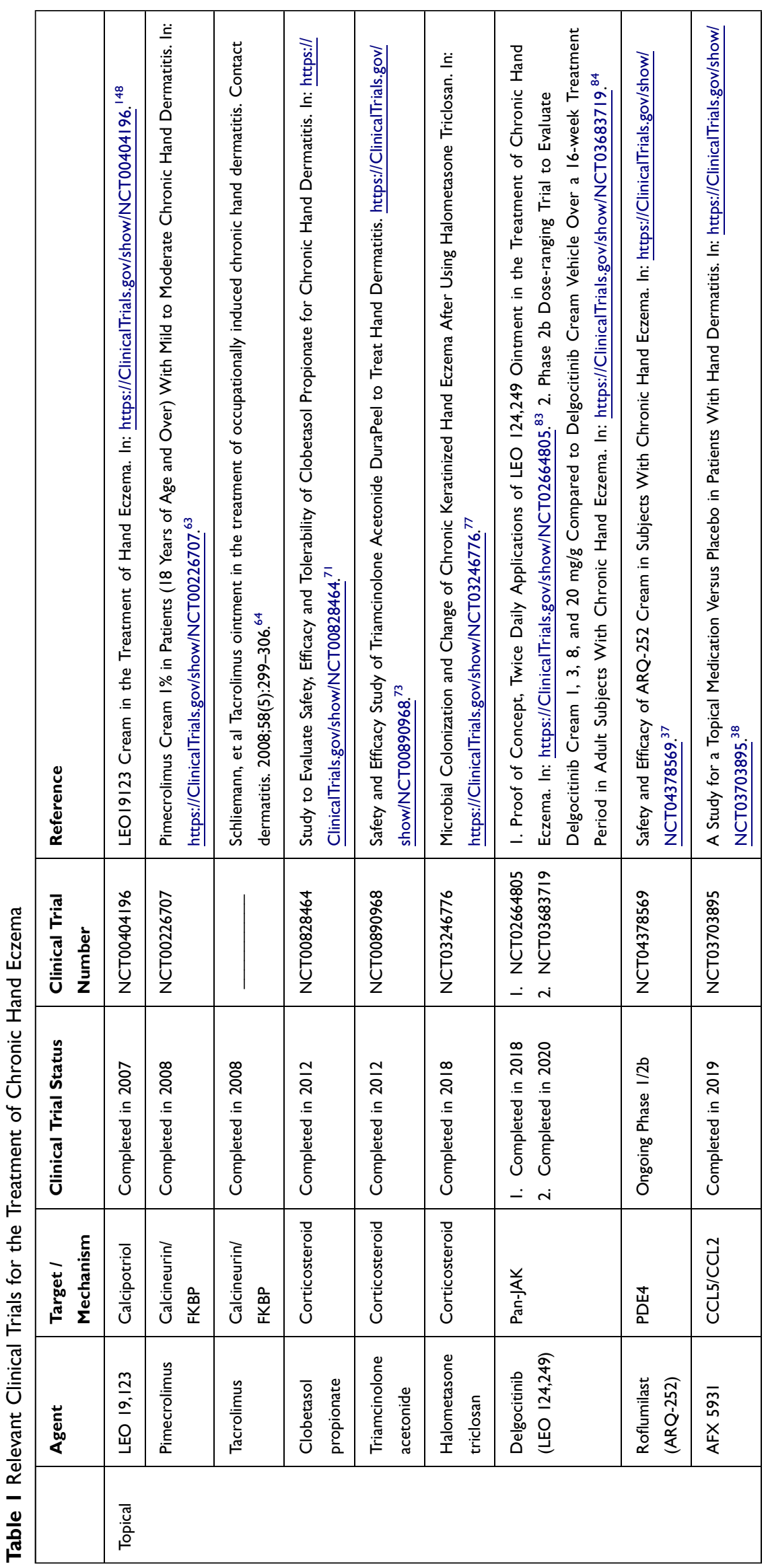




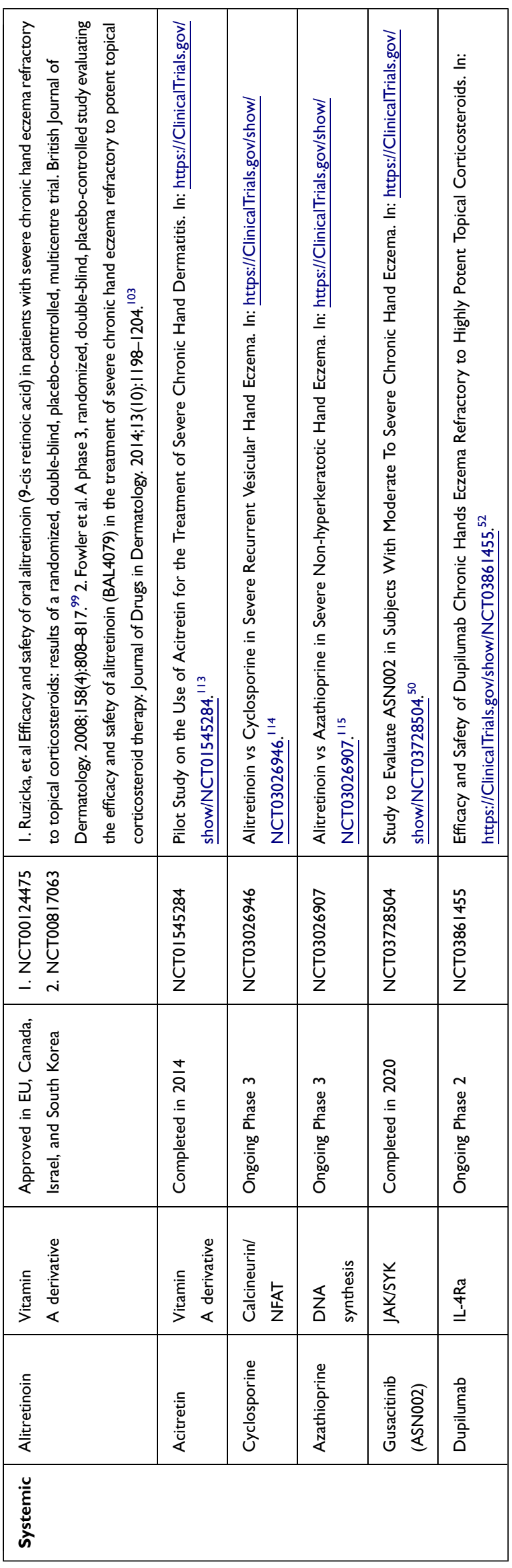

penetrate the epidermal barrier, allowing them to function as both topical and systemic treatments for CHE. Though there have been only few mild reported side effects from these treatments, due to their being topical drugs, patient compliance may be limited by the fact that hands are utilized and washed frequently throughout the day, which could compromise the efficacy of the treatment. Several clinical trials are currently ongoing to assess the efficacy and safety of these molecules in the treatment of CHE.

\section{Delgocitinib}

One of the most exciting advances in the treatment of CHE has been the positive data seen from the use of pan-JAK inhibitor delgocitinib. Delgocitinib is a small molecule panJAK inhibitor that non-selectively modulates Th2 signaling via blockage of JAK1, JAK2, and JAK3. ${ }^{1,34,35,82}$ It is able to do so by blocking the signaling of several inflammatory cytokines such as IL-4, IL6, IL-13, IL-22, IL-31, and IFN $\gamma$, thereby suppressing the inflammatory cascade and preventing the downregulation of important barrier genes. ${ }^{1,15,21,34,36}$ Targeting the JAK signaling pathways is an effective way to achieve a therapeutic response in a majority of patients, as it targets multiple cytokine pathways involved in CHE. ${ }^{15,21}$ One phase 2 proof-of-concept trial completed in 2016 evaluated the use of delgocitinib ointment for eight weeks in 91 patients with chronic hand eczema compared to placebo. ${ }^{83}$ Delgocitinib was found to improve disease severity in $45.7 \%$ of patients receiving the active treatment, compared to $14.9 \%$ in those receiving the placebo vehicle - this significant difference was seen in both irritant contact hand dermatitis as well as nonirritant type, suggesting its role as a therapeutic across CHE subtypes. ${ }^{34}$ Further, it was deemed both safe and effective, as only three treatment-related adverse events were reported and none were serious. Such mild adverse events of delgocinitib include nasopharyngitis and headache, seen in a small minority of patients. ${ }^{34} \mathrm{~A}$ more recent phase 2 randomized parallel assignment trial, completed in 2020, investigated the use of delgocitinib versus placebo in 258 patients with mild to severe chronic hand eczema over 16 weeks. The primary endpoint of this trial was to assess symptom improvement via the Investigator's Global Assessment (IGA) score. ${ }^{84}$ Results have not yet been published of this most recent trial.

\section{Roflumilast}

Roflumilast is a high potency selective inhibitor of the PDE4 receptor, which functions by degrading cyclic adenosine monophosphate (cAMP). ${ }^{85,86}$ Blocking the 
PDE-4 receptor allows cAMP to signal the transcription of immune function genes such as anti-inflammatory IL10, while simultaneously reducing the production of inflammatory cytokines such as TNF $\alpha$ and IFN $\gamma$, which have been identified as possible involved in CHE. $^{15,87,88}$ Roflumilast has been investigated as a topical therapeutic for $\mathrm{AD}$, but showed little to no efficacy. ${ }^{89}$ It is currently being evaluated in a Phase 1/ $2 \mathrm{~b}$ randomized parallel assignment trial involving 221 patients with chronic hand eczema. ${ }^{37}$ Patients were randomized to receive one of two doses of topical roflumilast cream (ARQ-252) cream, $0.1 \%$ or $0.3 \%$, or topical placebo for 2 weeks (phase 1) and 12 weeks (phase 2b). The primary outcome measures are safety and IGA score of either 0 "clear" or 1 "almost clear" skin after 12 weeks. This trial was recently started and is still ongoing, and results have not yet been published (Table 1)..$^{37,90}$

\section{AFX5931}

Another investigational small molecule treatment targets cytokines directly to decrease the heightened inflammation involved in CHE. A recently developed topical antiinflammatory, AFX5931, directly targets CCL5 and CCL2, two key inflammatory cytokines involved in the pathogenesis of allergen and irritant contact dermatitis. $^{91-93}$ One Phase 4 clinical trial completed in 2019 compared the use of this topical anti-inflammatory to placebo. ${ }^{38}$ In a $3: 1$ randomization, 15 subjects received the active treatment while 5 subjects received the vehicle placebo, and efficacy was assessed using the Investigator's Global Assessment and Hand Eczema Severity Index. Phase 4 results have not yet been published (Table 1). ${ }^{38}$

\section{Existing Systemic Therapeutics}

Systemic therapeutics are often needed to control moderate-to-severe CHE that is refractory to topicals. However, there are no FDA approved systemic treatments for CHE. Several systemic drugs are currently under clinical investigation, holding promise for the treatment of $\mathrm{CHE}$. Systemics may require less frequent and precise patient compliance, ${ }^{94}$ but they are often associated with a higher side effect profile, which can be a deterrent for patients.

One systemic therapeutic, alitretinoin, a retinoid vitamin A derivative, is approved for moderate-to-severe $\mathrm{CHE}$ in Europe, Canada, Israel, and South Korea, ${ }^{95-98}$ showing efficacy in treating refractory $\mathrm{CHE}$ in several large studies, as below. Retinoids are systemic vitamin A derivatives that treat $\mathrm{CHE}$ by targeting the retinoic acid receptors A and/or X, which have been found to be downregulated in CHE skin. ${ }^{98,99}$ Targeting these receptors decreases inflammation by inhibiting keratinocyte-derived vascular endothelial growth factor, inhibiting keratin gene expression, and decreasing levels of IgE, Th2, and Th17 cells, while also increasing levels of Treg cells. ${ }^{1,100-102}$ Several studies have shown alitretinoin to be efficacious in the treatment of CHE. ${ }^{99-101,103-106}$ The most recent large Phase 3 trial completed internationally studied the safety and efficacy of oral alitretinoin in 1032 patients randomized to receive $10 \mathrm{mg}$ alitretinoin, $30 \mathrm{mg}$ alitretinoin, or a placebo pill once a day for 24 weeks. Improvement was measured by PGA, and $48 \%$ of participants achieved a score of "clear" (0) or "almost clear" (1) after $30 \mathrm{mg}$ of alitretinoin every day compared to only $17 \%$ of participants receiving placebo, with a dose-dependent response as well as a dose dependent side effect profile, including headaches, mucocutaneous events such as cheilitis and dry skin, hyperlipidemia, and decreased TSH and free thyroxine. $^{99}$ Though this trial and others internationally have shown therapeutic efficacy with its use, alitretinoin has a barrage of adverse effects including teratogenicity, xerosis, alopecia, cheilitis, myalgias, suicidality, headaches, and serum abnormalities such as elevated lipids and LFTs, and leukopenia. ${ }^{99-101,107-109}$ The possible side effects of this medication make it a suboptimal option as a long-term treatment for chronic hand eczema. ${ }^{97}$

Another systemic retinoid, acitretin, has been approved for psoriasis and has shown some efficacy in severe CHE as well. ${ }^{96,110,111}$ Acitretin differs from alitretinoin in that it targets specifically the A retinoic acid receptors, but it has a similar effect of decreasing cellular differentiation, keratinization, and inflammation, and reducing Th1 and Th17 cell infiltration. ${ }^{96,112}$ Clinical trials conducted in Europe have assessed the use of acitretin, and though a reduction in symptoms was seen in patients compared to placebo, a lower percentage of patients experienced complete clearing of eczema than other systemic therapeutics. ${ }^{112,113}$ Like alitretinoin, the severe adverse effects likely outweigh the therapeutic efficacy - one review found that $43.1 \%$ of patients discontinued treatment with acitretin in the first few months of use due to adverse effects, such as xerosis or dermatitis. ${ }^{96,110}$ Due to their side effect profile, retinoids are an undesirable option for long-term treatment of $\mathrm{CHE}$.

Two systemic broad immunosuppressants have also been tested as therapeutic options for moderate-to-severe CHE: cyclosporine and azathioprine. ${ }^{114,115}$ Both are oral 
medications that suppress systemic inflammation, and both have been previously been explored as treatment options for atopic dermatitis. Systemic immunosuppressants have a variety of adverse effects and are often poorly tolerated, and further, they are non-specific and therefore are not as efficacious as other targeted systemics. ${ }^{78,116-120}$ Apremilast, a small molecule systemic drug that has showed a good safety profile in the treatment of psoriasis, ${ }^{121-123}$ has also been seen in clinical case series to successfully treat CHE, showing $90 \%$ clearance and a reduction in pruritus. ${ }^{124,125}$

Methotrexate and systemic corticosteroids have also been empirically used for the treatment of moderate-tosevere chronic hand eczema. ${ }^{82,126-129}$ Although smaller scale studies, case reports, and retrospective reviews have found modest efficacy in their use, neither has been formally investigated in a registered clinical trial for the treatment of CHE. ${ }^{82,126,130,131}$

\section{Novel Systemic Therapeutics}

The successful use of biologics and JAK-inhibitors in several inflammatory skin diseases, such as AD and psoriasis, is currently also being adopted for the treatment of severe CHE, with several drugs under investigation.

\section{Small Molecules \\ Gusacitinib}

A recent addition to the systemic treatments used for chronic hand eczema is gusacitinib (ASN002), an oral medication that blocks the JAK and SYK signaling pathways. ${ }^{132,133}$ Blocking SYK effectively inhibits IL-17 signaling, while blocking JAK inhibits Th1, Th2, and Th22 signaling, all of which are implicated in the immune pathogenesis of CHE across its various etiologies. ${ }^{133,134}$ As a JAK/SYK inhibitor, gusacitinib can have immunosuppressant side effects such as lymphocytopenia. Further, though it is often well tolerated by patients, mild-to-moderate adverse events have been reported, including headaches, nausea, diarrhea, and mild hypertension. ${ }^{135-137}$ A phase $2 \mathrm{~b}$ clinical trial recently completed in mid-2020 evaluated the efficacy, safety, and tolerability of once daily oral gusacitinib in 97 participants with moderate-to-severe chronic hand eczema otherwise refractory to topical therapeutics. ${ }^{50}$ Participants were randomized to receive $40 \mathrm{mg}$ of gusacitinib, $80 \mathrm{mg}$ of gusacitinib, or a placebo tablet for 32 weeks, and symptomatic change from baseline was measured using the mTLSS and PGA (Table 1) ${ }^{50}$ Topline results from this trial showed dosedependent improvements in mTLSS and PGA from baseline in patients receiving both $80 \mathrm{mg}$ and $40 \mathrm{mg}$ of gusacitinib, compared to placebo, after 16 weeks. They also found that the drug was safe and well-tolerated. ${ }^{47}$

\section{Biologics \\ Dupilumab}

Dupilumab is a monoclonal antibody that directly inhibits IL4 and IL-13, two crucial cytokines in the Th2 signaling immune pathway that are implicated in the pathogenesis of allergic contact hand dermatitis and atopic hand dermatitis. $^{21,46,138,139}$ Not only does dupilumab directly decrease Th2 signaling, it also indirectly decreases Th17 and Th22 signaling, and decreases epidermal proliferation while increasing epidermal differentiation. ${ }^{138}$ Dupilumab is FDA approved to treat atopic dermatitis, and generally has a favorable safety profile, though injection-site erythema, conjunctivitis, and, rarely, head and neck dermatitis have been frequently reported. ${ }^{140-142}$ Of note, though dupilumab is more costly than some older systemic drugs, such as cyclosporine or methotrexate, the longer term safety profile and significant efficacy in clearing severe disease increase the cost efficacy of dupilumab use. ${ }^{143,144}$

Dupilumab has been seen in several case studies to improve severe CHE that is otherwise refractory to highly potent topical therapeutics. ${ }^{49,53,139}$ Also, observational studies of AD patients with comorbid hand eczema on dupilumab have seen significant improvements in hand eczema, as measured by the hand eczema severity index (HECSI-75) and quality of life measures. ${ }^{46}$ The findings in these case and observational studies have motivated an ongoing phase 2 clinical trial involving 94 participants with moderate-tosevere CHE. ${ }^{52}$ Participants were given a $300 \mathrm{mg}$ dose of dupilumab IM every 2 weeks or a placebo injection every 2 weeks, after a $600 \mathrm{mg}$ loading dose, for a total of 16 weeks. Change in clinical severity was assessed using the modified Total Lesion Symptom Score (mTLSS) change from baseline as a primary endpoint, with pruritis, pain, quality of life, sleep loss, IGA, PaGA, EASI, and IgE levels as secondary endpoints (Table 1). ${ }^{52}$ The study is ongoing and preliminary results have not yet been published, but the emerging anecdotal evidence of its efficacy in CHE makes dupilumab a possible treatment option for moderate-to-severe resistant CHE.

\section{Conclusion}

Chronic hand eczema (CHE) is a common skin condition that affects up to $10 \%$ of the population. ${ }^{1-4}$ It carries a significant burden, as affected individuals are often 
unable to work or struggle to complete some activities of daily living due to the impact of CHE on their hands. ${ }^{2,6-8}$ Despite some similarities to $\mathrm{AD}$, it is a heterogenous disease with a pathophysiology that is not yet fully studied. The multi-faceted immune profile of chronic hand eczema across its different etiologies complicates the process of developing a single treatment regimen with a high safety profile, that can work across all etiologies.

Thus far, several topical and systemic therapeutics have been proposed for the treatment of moderate as well as moderate-to-severe CHE, but, still, with few compelling results. Topical steroids - particularly higher potency steroids such as clobetasol propionate - have long demonstrated efficacy, particularly for mild-tomoderate cases, but are associated with adverse effects. $^{33,69,145-147}$ The adverse effects associated with topical steroids, including skin atrophy and tachyphylaxis, hinder longer term use, which is often required for the treatment of CHE. ${ }^{69,70,146}$ Non-steroidal topical treatments such as calcineurin inhibitors and calcipotriol have also shown limited efficacy, but current treatment regimens are not standardized..$^{33,61,64,148,149}$ Of note, a unique challenge of treating CHE with any topical drug is ensuring patients' compliance due to difficulty of keeping the therapy on the hands entirely, as hands are used and washed throughout the day, which may detract from the efficacy of a topical treatment. They are also limited in that they are used for mild-to-moderate hand eczema only, and more severe cases are typically resistant to topical therapies. Recent advances have been made with the topical pan-JAK inhibitor delgocitinib. It has emerged as a potential treatment for mild-to-severe disease, showing high efficacy with a favorable side effect profile.

Positive data for moderate-to-severe CHE has been shown outside of the US through the utilization of alitretinoin, which is a relatively cost-effective systemic drug that has shown efficacy in treating refractory, chronic moderate-to-severe cases of hand eczema. ${ }^{99-101,103,147,150}$ However, it has safety concerns, particularly for women of childbearing age who must adhere to strict birth control measures. ${ }^{100,104,151}$ Gusacitinib and dupilumab are emerging as possible effective treatment options for CHE, ${ }^{34,35,46,49,53,125,132,138}$ but are still in early phases of study and are financially costly for patients. ${ }^{143,144}$

The significant disease burden of chronic and moderateto-severe cases, in combination with the frequent lack of response of such cases to topical therapeutics, advocates for a new treatment paradigm. Previous research on other inflammatory skin conditions, including $\mathrm{AD}$ and psoriasis, have made massive strides in developing effective, safe, and highly targeted treatments through the use of biomarkers that helped define disease patho-mechanisms. In CHE, such an approach is similarly needed, perhaps through minimally invasive biomarkers, such as tape strips. Tape strips are becoming more frequently used to study biomarker expression in skin diseases allowing for a more comprehensive understanding of its pathogenesis and paving the way for future treatment development. ${ }^{152-157}$ Increasing the understanding of underlying immune profiles of the different CHE phenotypes will allow for the development of valuable therapeutics and continued investigation of immune-based therapeutics such as delgocitinib, gusacitinib, and dupilumab.

\section{Clinical Perspective and Future Directions}

While the spectrum of therapeutic options for CHE has expanded in recent years, this condition is still an open challenge for physicians and patients alike. The limited number of effective therapeutics, the relapsing-remitting course of the disease, along with the low compliance to therapy, represent unmet needs with deleterious impacts on patients' quality of life. In light of the multiple pathogenetic factors at play in CHE (for example, atopic and nonatopic types), the therapeutic flowchart encompassing topical, phototherapy, and systemic treatments should be actively followed by the physician in order to ensure an effective intervention. Physicians should also encourage simultaneous preventative and hygiene measures, including hand moisturizing, avoiding excessive washing, and using mild-strength soaps and washes. These measures are synergistic with the use of topical and systemic drugs.

The heterogeneity of CHE can also hinder a timely diagnosis due to the wide range of CHE causes. This delay leads patients to be discouraged from pursuing treatment and causes a drop off in therapeutic adherence. The negative impact that this condition has on patients goes beyond the physical impairment caused by the eczema. Patients are often unable to work, have difficulty sleeping, and experience social embarrassment and shame around the appearance of their hands. This takes both a financial and emotional toll on patients. The enormous psychological burden of the condition makes CHE incredibly challenging to treat, as it is crucial to balance treatment trial and error with patient quality of life. 
Thus, while topical treatments still find space in the treatment of mild CHE, systemic therapy should be discussed at the early stage with moderate-to-severe CHE patients, before the condition worsens. The broad immunomodulators azathioprine and cyclosporine, in addition to retinoids, are accepted as off-label treatments of CHE, but their use is compromised by severe long-term side effects. With the advent of more targeted therapies such as small molecules and biologics, we can modify the treatment paradigm of CHE, but more research into their efficacy across CHE phenotypes is needed.

In order to develop these targeted treatments, it is important to identify the molecular and cellular aspects that differentiate the various immune phenotypes of this condition. Due to the unique features of the hands, a minimally invasive diagnostic tool that is welltolerated by patients and does not increase risk of infection or scarring would be ideal. Major strides have been made in the field of dermatology through the use of tape strips to characterize the immune and barrier gene profiles in various skin conditions - such an approach should be similarly applied to CHE. Future studies in CHE should focus on identifying the immune and barrier abnormalities of the condition that differentiate the various clinical phenotypes. The identification of specific upregulated biomarkers may also reveal reliable markers for clinical monitoring. This methodology would allow for an improvement in the process of drug development and encouraging treatment adherence. It is conceivable that in the next several years, other therapeutics - both topical and systemic - will be developed that are specifically tailored to the underlying pathogenesis of a given $\mathrm{CHE}$ etiology.

\section{Abbreviations}

$\mathrm{ACD}$, allergic contact dermatitis; CHE, chronic hand eczema; ICD, irritant contact dermatitis; JAK, janus kinase; SYK, spleen tyrosine kinase.

\section{Author Contributions}

All authors made a significant contribution to the work reported, whether that is in the conception, study design, execution, acquisition of data, analysis and interpretation, or in all these areas; took part in drafting, revising or critically reviewing the article; gave final approval of the version to be published; have agreed on the journal to which the article has been submitted; and agree to be accountable for all aspects of the work.

\section{Disclosure}

Celina Dubin and Ester Del Duca report no conflicts of interest for this work. Emma Guttman-Yassky is an employee of Mount Sinai and has received research funds (grants paid to the institution) from Abbvie, Almirall, Amgen, AnaptysBio, Asana Biosciences, Boehringer-Ingelheim, Celgene, Dermavant, DS Biopharma, Eli Lilly, Galderma, Ichnos Sciences, Innovaderm, Janssen, Kiniska, Kyowa Kirin, Leo Pharma, Novan, Pfizer, Ralexar, Regeneron Pharmaceuticals, Inc., Sienna Biopharma, UCB and Union Therapeutics; and is a consultant for Abbvie, Aditum Bio, Almirall, Amgen, Asana Biosciences, AstraZeneca, Boehringer-Ingelheim, Cara Therapeutics, Celgene, Concert, DBV, Dermira, DS Biopharma, Eli Lilly, EMD Serono, Escalier, Galderma, Ichnos Sciences, Incyte Kyowa Kirin, Leo Pharma, Mitsubishi Tanabe, Pandion Therapeutics, Pfizer, RAPT Therapeutics, Regeneron Pharmaceuticals, Inc., Sanofi, Sienna Biopharma, Target PharmaSolutions and Union Therapeutics, and reports no other potential conflicts of interest for this work.

\section{References}

1. Lee GR, Maarouf M, Hendricks AK, Lee DE, Shi VY. Current and emerging therapies for hand eczema. Dermatol Ther. 2019;32 (3):e12840. doi:10.1111/dth.12840

2. Diepgen TL, Agner T, Aberer W, et al. Management of chronic hand eczema. Contact Dermatitis. 2007;57(4):203-210. doi:10.11 11/j.1600-0536.2007.01179.x

3. Thyssen JP, Johansen JD, Linneberg A, Menne T. The epidemiology of hand eczema in the general population-prevalence and main findings. Contact Dermatitis. 2010;62(2):75-87. doi:10.11 11/j.1600-0536.2009.01669.x

4. Coenraads PJ. Hand eczema. $N$ Engl J Med. 2012;367 (19):1829-1837. doi:10.1056/NEJMcp1104084

5. Schuttelaar ML, Coenraads PJ, Huizinga J, De Monchy JG, Vermeulen KM. Increase in vesicular hand eczema after house dust mite inhalation provocation: a double-blind, placebo-controlled, cross-over study. Contact Dermatitis. 2013;68(2):76-85. doi:10.11 11/j.1600-0536.2012.02172.x

6. Agner T, Andersen KE, Brandao FM, et al. Hand eczema severity and quality of life: a cross-sectional, multicentre study of hand eczema patients. Contact Dermatitis. 2008;59(1):43-47. doi:10. 1111/j.1600-0536.2008.01362.x

7. Cvetkovski RS, Zachariae R, Jensen H, Olsen J, Johansen JD, Agner T. Quality of life and depression in a population of occupational hand eczema patients. Contact Dermatitis. 2006;54 (2):106-111. doi:10.1111/j.0105-1873.2006.00783.x

8. Skoet R, Zachariae R, Agner T. Contact dermatitis and quality of life: a structured review of the literature. Br J Dermatol. 2003;149 (3):452-456. doi:10.1046/j.1365-2133.2003.05601.x

9. Agner T, Elsner P. Hand eczema: epidemiology, prognosis and prevention. J Eur Acad Dermatol Venereol. 2020;34(Suppl 1):4-12. doi:10.1111/jdv.16061

10. Kang YC, Lee S, Ahn SK, Choi EH. Clinical manifestations of hand eczema compared by etiologic classification and irritation reactivity to SLS. J Dermatol. 2002;29(8):477-483. doi:10.1111/ j.1346-8138.2002.tb00312.x 
11. Svensson A. Hand eczema: an evaluation of the frequency of atopic background and the difference in clinical pattern between patients with and without atopic dermatitis. Acta Derm Venereol. 1988;68(6):509-513.

12. Coenraads P-J. Hand eczema is common and multifactorial. J Investig Dermatol. 2007;127(7):1568-1570. doi:10.1038/sj. jid. 5700781

13. Veien NK, Hattel T, Laurberg G. Hand eczema: causes, course, and prognosis I. Contact Dermatitis. 2008;58(6):330-334. doi:10.1111/j.1600-0536.2008.01345.x

14. Wollenberg A, Blauvelt A, Guttman-Yassky E, et al. Tralokinumab for moderate-to-severe atopic dermatitis: results from two 52-week, randomized, double-blind, multicentre, placebo-controlled Phase III trials (ECZTRA 1 and ECZTRA 2). $\mathrm{Br}$ J Dermatol. 2020. doi:10.1111/bjd.19574

15. Dhingra N, Shemer A, Correa da Rosa J, et al. Molecular profiling of contact dermatitis skin identifies allergen-dependent differences in immune response. J Allergy Clin Immunol. 2014;134 (2):362-372. doi:10.1016/j.jaci.2014.03.009

16. Molin S, Diepgen TL, Ruzicka T, Prinz JC. Diagnosing chronic hand eczema by an algorithm: a tool for classification in clinical practice. Clin Exp Dermatol. 2011;36(6):595-601. doi:10.1111/ j.1365-2230.2010.04001.x

17. Svensson A. Hand eczema: an evaluation of the frequency of atopic background and the difference in clinical pattern between patients with and without atopic dermatitis. Acta Derm Venereol. 1988;68(6):509.

18. Abramovits W, Stevenson LC. Atopic profiles, familial histories, and coexisting conditions associated with hand eczema. Skinmed. 2005;4(4):204-210. doi:10.1111/j.1540-9740.2005.03635.x

19. Coenraads PJ, Diepgen TL. Risk for hand eczema in employees with past or present atopic dermatitis. Int Arch Occup Environ Health. 1998;71(1):7-13. doi:10.1007/s004200050243

20. Belsito DV. Occupational contact dermatitis: etiology, prevalence, and resultant impairment/disability. $J$ Am Acad Dermatol. 2005;53(2):303-313. doi:10.1016/j.jaad.2005.02.045

21. Leonard A, Guttman-Yassky E. The unique molecular signatures of contact dermatitis and implications for treatment. Clin Rev Allergy Immunol. 2019;56(1):1-8. doi:10.1007/s12016-018-8685-0

22. Gittler JK, Krueger JG, Guttman-Yassky E. Atopic dermatitis results in intrinsic barrier and immune abnormalities: implications for contact dermatitis. $J$ Allergy Clin Immunol. 2013;131 (2):300-313. doi:10.1016/j.jaci.2012.06.048

23. DeJongh CM, John SM, Bruynzeel DP, et al. Cytokine gene polymorphisms and susceptibility to chronic irritant contact dermatitis. Contact Dermatitis. 2008;58(5):269-277. doi:10.11 11/j.1600-0536.2008.01317.x

24. Ungar B, Correa da Rosa J, Shemer A, et al. Patch testing of food allergens promotes Th17 and Th2 responses with increased IL-33: a pilot study. Exp Dermatol. 2017;26(3):272-275. doi:10.1111/ exd. 13148

25. Molin S, Merl J, Dietrich KA, et al. The hand eczema proteome: imbalance of epidermal barrier proteins. Br J Dermatol. 2015;172 (4):994-1001. doi:10.1111/bjd.13418

26. Wang X, Ye L, Lai Q, et al. Altered epidermal permeability barrier function in the uninvolved skin supports a role of epidermal dysfunction in the pathogenesis of occupational hand eczema. Skin Pharmacol Physiol. 2020;33(2):94-101. doi:10.1159/0005 06425

27. De Benedetto A, Rafaels NM, McGirt LY, et al. Tight junction defects in patients with atopic dermatitis. J Allergy Clin Immunol. 2011;127(3):773-777. doi:10.1016/j.jaci.2010.10.018

28. Cork MJ, Robinson DA, Vasilopoulos Y, et al. New perspectives on epidermal barrier dysfunction in atopic dermatitis: gene-environment interactions. $J$ Allergy Clin Immunol. 2006;118(1):3-21; quiz 22-23. doi:10.1016/j.jaci.2006.04.042
29. Tauber M, Berard E, Lourari S, et al. Latent class analysis categorizes chronic hand eczema patients according to skin barrier impairment. J Eur Acad Dermatol Venereol. 2020;34 (7):1529-1535. doi:10.1111/jdv.16083

30. Barrett A, Hahn-Pedersen J, Kragh N, Evans E, Gnanasakthy A. Patient-reported outcome measures in atopic dermatitis and chronic hand eczema in adults. Patient. 2019;12(5):445-459. doi:10.1007/s40271-019-00373-y

31. Diepgen TL, Andersen KE, Brandao FM, et al. Hand eczema classification: a cross-sectional, multicentre study of the aetiology and morphology of hand eczema. Br J Dermatol. 2009;160 (2):353-358. doi:10.1111/j.1365-2133.2008.08907.x

32. Thyssen JP, Silverberg JI, Guttman-Yassky E. Chronic hand eczema understanding has ramifications on clinical management. J Eur Acad Dermatol Venereol. 2020;34(8):e429-e430. doi:10.11 11/jdv. 16375

33. Christoffers WA, Coenraads PJ, Svensson A, et al. Interventions for hand eczema. Cochrane Database Syst Rev. 2019;4: CD004055. doi:10.1002/14651858.CD004055.pub2

34. Worm M, Bauer A, Elsner P, Mahler V, Molin S, Nielsen T. Topical delgocitinib is an efficacious and well tolerated treatment for patients with chronic hand eczema: 8467. J Am Acad Dermatol. 2019;81(4).

35. Worm M, Bauer A, Elsner P, Mahler V, Molin S, Nielsen TSS. Efficacy and safety of topical delgocitinib in patients with chronic hand eczema: data from a randomized, double-blind, vehicle-controlled phase IIa study. Br J Dermatol. 2020;182 (5):1103-1110. doi:10.1111/bjd.18469

36. Solimani F, Meier K, Ghoreschi K. Emerging topical and systemic JAK inhibitors in dermatology. Front Immunol. 2019;10:2847. doi:10.3389/fimmu.2019.02847

37. Safety and efficacy of ARQ-252 cream in subjects with chronic hand eczema. Available from: https:/ClinicalTrials.gov/show/ NCT04378569. Accessed December 21, 2020.

38. A study for a topical medication versus placebo in patients with hand dermatitis. Available from: https://ClinicalTrials.gov/show/ NCT03703895. Accessed December 21, 2020.

39. Yang M, Chang JM. Successful treatment of refractory chronic hand eczema with calcipotriol/betamethasone ointment: a report of three cases. Exp Ther Med. 2015;10(5):1943-1946. doi:10.38 92/etm.2015.2729

40. Gola M, Milanesi N, D’Erme AM. Clinical evaluation and assessment of the therapeutic efficacy of alitretinoin in a group of patients with chronic hand eczema refractory to topical steroid therapy. G Ital Dermatol Venereol. 2014;149(4):435-439.

41. Ham K, Maini P, Gooderham MJ. Real-world experience with alitretinoin in a community dermatology practice setting in patients with chronic hand dermatitis. J Cutan Med Surg. 2014;18(5):332-336. doi:10.2310/7750.2014.13195

42. Christoffers WA, Politiek K, Coenraads PJ, van der Schaft J, de Bruin-weller MS, Schuttelaar ML. Drug survival of cyclosporine in the treatment of hand eczema: a multicentre, daily use study. J Eur Acad Dermatol Venereol. 2016;30(1):63-66. doi:10.1111/ jdv. 13057

43. Granlund H, Erkko P, Eriksson E, Reitamo S. Comparison of cyclosporine and topical betamethasone-17,21-dipropionate in the treatment of severe chronic hand eczema. Acta Derm Venereol. 1996;76(5):371-376. doi:10.2340/0001555576371376

44. Gooderham M, Lynde CW, Papp K, et al. Review of systemic treatment options for adult atopic dermatitis. J Cutan Med Surg. 2017;21(1):31-39. doi:10.1177/1203475416670364

45. Oosterhaven JA, Politiek K, Schuttelaar MA. Azathioprine treatment and drug survival in patients with chronic hand eczema results from daily practice. Contact Dermatitis. 2017;76 (5):304-307. doi:10.1111/cod.12691 
46. Oosterhaven JAF, Voorberg AN, Romeijn GLE, de Bruinweller MS, Schuttelaar MLA. Effect of dupilumab on hand eczema in patients with atopic dermatitis: an observational study. J Dermatol. 2019;46(8):680-685. doi:10.1111/13468138.14982

47. Asana biosciences announces positive topline results from phase $2 b$ study of oral JAK/SYK inhibitor gusacitinib (ASN002) in patients with chronic hand eczema: rapid and significant improvement demonstrated [press release] Business Wire. 2020.

48. Loman L, Diercks GFH, Schuttelaar MLA. Three cases of non-atopic hyperkeratotic hand eczema treated with dupilumab. Contact Dermatitis. 2020. doi:10.1111/cod.13693

49. Oosterhaven JAF, Romeijn GLE, Schuttelaar MLA. Dupilumab treatment of very severe refractory atopic hand eczema. JAMA Dermatol. 2018;154(8):969-970. doi:10.1001/jamadermatol.20 18.2027

50. Study to evaluate ASN002 in subjects with moderate to severe chronic hand eczema. Available from: https://ClinicalTrials.gov/ show/NCT03728504. Accessed December 21, 2020.

51. Pavel AB, Song T, Kim HJ, et al. Oral Janus kinase/SYK inhibition (ASN002) suppresses inflammation and improves epidermal barrier markers in patients with atopic dermatitis. J Allergy Clin Immunol. 2019;144:1011-1024. doi:10.1016/j.jaci.2019.07.013

52. Efficacy and safety of dupilumab chronic hands eczema refractory to highly potent topical corticosteroids. Available from: https:// ClinicalTrials.gov/show/NCT03861455. Accessed December 21, 2020.

53. Zirwas MJ. Dupilumab for hand eczema. J Am Acad Dermatol. 2018;79(1):167-169. doi:10.1016/j.jaad.2018.02.073

54. Egawa K. Topical vitamin D3 derivatives in treating hyperkeratotic palmoplantar eczema: a report of five patients. $J$ Dermatol. 2005;32(5):381-386. doi:10.1111/j.1346-8138.20 05.tb00911.x

55. Juntongjin P, Pongprasert R. Calcipotriol ointment shows comparable efficacy to topical steroids in chronic hand eczema. Dermatol Ther. 2019;32(4):e12956. doi:10.1111/dth.12956

56. Pongprasert R, Juntongjin P. Calcipotriol: a promising treatment for hand eczema. 2017.

57. Nghiem P, Pearson G, Langley RG. Tacrolimus and pimecrolimus: from clever prokaryotes to inhibiting calcineurin and treating atopic dermatitis. $J$ Am Acad Dermatol. 2002;46(2):228-241. doi:10.1067/mjd.2002.120942

58. Wollina U. The role of topical calcineurin inhibitors for skin diseases other than atopic dermatitis. Am J Clin Dermatol. 2007;8(3):157-173. doi:10.2165/00128071-200708030-00003

59. Warshaw EM. Therapeutic options for chronic hand dermatitis. Dermatol Ther. 2004;17(3):240-250. doi:10.1111/j.1396-0296.20 04.04025.x

60. Hultsch T, Kapp A, Spergel J. Immunomodulation and safety of topical calcineurin inhibitors for the treatment of atopic dermatitis. Dermatology. 2005;211(2):174-187. doi:10.1159/000 086739

61. Belsito DV, Fowler JF, Marks JG, et al. Pimecrolimus cream 1\%: a potential new treatment for chronic hand dermatitis. Cutis. 2004;73(1):31-38.

62. Wellington K, Jarvis B. Topical pimecrolimus. Drugs. 2002;62 (5):817-840. doi:10.2165/00003495-200262050-00007

63. Pimecrolimus cream $1 \%$ in patients ( 18 years of age and over) with mild to moderate chronic hand dermatitis. Available from: https:// ClinicalTrials.gov/show/NCT00226707. Accessed December 21, 2020.

64. Schliemann S, Kelterer D, Bauer A, et al. Tacrolimus ointment in the treatment of occupationally induced chronic hand dermatitis. Contact Dermatitis. 2008;58(5):299-306. doi:10.1111/j.16000536.2007.01314.x
65. Thelmo MC, Lang W, Brooke E, et al. An open-label pilot study to evaluate the safety and efficacy of topically applied tacrolimus ointment for the treatment of hand and/or foot eczema. J Dermatolog Treat. 2003;14(3):136-140. doi:10.1080/0954663 0310009491

66. Gabros S, Nessel TA, Zito PM. Topical corticosteroids. In: StatPearls. Treasure Island (FL); 2020.

67. Hoare C, Li Wan Po A, Williams H. Systematic review of treatments for atopic eczema. Health Technol Assess. 2000;4 (37):1-191. doi:10.3310/hta4370

68. Perry AD, Trafeli JP. Hand dermatitis: review of etiology, diagnosis, and treatment. J Am Board Fam Med. 2009;22(3):325-330. doi:10.3122/jabfm.2009.03.080118

69. English J, Aldridge R, Gawkrodger DJ, et al. Consensus statement on the management of chronic hand eczema. Clin Exp Dermatol. 2009;34(7):761-769. doi:10.1111/j.1365-2230.2009.03 649.x

70. Ference JD, Last AR. Choosing topical corticosteroids. Am Fam Physician. 2009;79(2):135-140.

71. Study to evaluate safety, efficacy and tolerability of clobetasol propionate for chronic hand dermatitis. Available from: https:// ClinicalTrials.gov/show/NCT00828464. Accessed December 21, 2020.

72. Kircik LH, Tropmann C. Treatment of mild-to-moderate chronic hand dermatitis with clobetasol propionate $0.05 \% \mathrm{EF}$ foam: results from an open-label study. $J$ Drugs Dermatol. 2011;10 (12):1398-1402.

73. Safety and efficacy study of triamcinolone acetonide durapeel to treat hand dermatitis. Available from: https://ClinicalTrials.gov/ show/NCT00890968. Accessed December 21, 2020.

74. Cohen DE, Heidary N. Treatment of irritant and allergic contact dermatitis. Dermatol Ther. 2004;17(4):334-340. doi:10.1111/ j.1396-0296.2004.04031.x

75. Chen Y, Wang X, Zhang C, Shi W. Detection and treatment of Staphylococcus aureus colonization in chronic hand eczema: a multicenter study. J Dermatolog Treat. 2019;30(6):565-567. doi:10.1080/09546634.2018.1476650

76. Wang X, Xu W, Chen Y, et al. Staphylococcus aureus colonization and chronic hand eczema: a multicenter clinical trial. Arch Dermatol Res. 2019;311(7):513-518. doi:10.1007/s00403-01901924-x

77. Microbial colonization and change of chronic keratinized hand eczema after using halometasone triclosan. Available from: https:// ClinicalTrials.gov/show/NCT03246776. Accessed December 21, 2020.

78. Paller AS, Kabashima K, Bieber T. Therapeutic pipeline for atopic dermatitis: end of the drought? $J$ Allergy and Clin Immunol. 2017;140(3):633-643. doi:10.1016/j.jaci.2017.07.006

79. Soeberdt M, Kilic A, Abels C. Small molecule drugs for the treatment of pruritus in patients with atopic dermatitis. Eur J Pharmacol. 2020;881:173242. doi:10.1016/j.ejphar.2020.173242

80. Vávrová K. Emerging small-molecule compounds for treatment of atopic dermatitis: a review. Expert Opin Ther Pat. 2016;26 (1):21-34. doi:10.1517/13543776.2016.1101451

81. Hoppmann J, Baumer W, Galetzka C, Hofgen N, Kietzmann M, Rundfeldt C. The phosphodiesterase 4 inhibitor AWD 12-281 is active in a new guinea-pig model of allergic skin inflammation predictive of human skin penetration and suppresses both Th1 and Th2 cytokines in mice. J Pharm Pharmacol. 2005;57(12): 1609-1617. doi:10.1211/jpp.57.12.0011

82. Elsner P, Agner T. Hand eczema: treatment. J Eur Acad Dermatol Venereol. 2020;34(Suppl 1):13-21. doi:10.1111/jdv.16062

83. Proof of concept, twice daily applications of LEO 124249 ointment in the treatment of chronic hand eczema. Available from: https:// ClinicalTrials.gov/show/NCT02664805. Accessed December 21, 2020. 
84. Phase $2 \mathrm{~b}$ dose-ranging trial to evaluate delgocitinib cream $1,3,8$, and $20 \mathrm{mg} / \mathrm{g}$ compared to delgocitinib cream vehicle over a 16-week treatment period in adult subjects with chronic hand eczema. Available from: https://ClinicalTrials.gov/show/ NCT03683719. Accessed December 21, 2020.

85. Diaz A, Guttman-Yassky E. Topical agents for the treatment of atopic dermatitis. Expert Rev Clin Immunol. 2019;15(4):369-382. doi:10.1080/1744666X.2019.1564038

86. Hanifin JM, Chan SC, Cheng JB, et al. Type 4 phosphodiesterase inhibitors have clinical and in vitro anti-inflammatory effects in atopic dermatitis. $J$ Invest Dermatol. 1996;107(1):51-56. doi:10.1111/1523-1747.ep12297888

87. Sakkas I, Mavropoulos A, Bogdanos D. Phosphodiesterase 4 inhibitors in immune-mediated diseases: mode of action, clinical applications, current and future perspectives. Curr Med Chem. 2017;24 (28):3054-3067. doi:10.2174/0929867324666170530093902

88. Kofoed K, Skov L, Zachariae C. New drugs and treatment targets in psoriasis. Acta Derm Venereol. 2015;95(2):133-139. doi:10.23 40/00015555-1931

89. Yang H, Wang J, Zhang X, et al. Application of topical phosphodiesterase 4 inhibitors in mild to moderate atopic dermatitis: a systematic review and meta-analysis. JAMA Dermatol. 2019;155(5):585-593. doi:10.1001/jamadermatol.2019.0008

90. Arcutis completes enrollment in phase $1 / 2 \mathrm{~b}$ study evaluating ARQ-252 in chronic hand eczema [press release]. Westlake Village, CA. 2020.

91. Nedoszytko B, Sokolowska-Wojdylo M, RuckemannDziurdzinska K, Roszkiewicz J, Nowicki RJ. Chemokines and cytokines network in the pathogenesis of the inflammatory skin diseases: atopic dermatitis, psoriasis and skin mastocytosis. Postepy Dermatol Alergol. 2014;2(2):84-91. doi:10.5114/pdia.20 14.40920

92. Ouwehand K, Scheper RJ, de Gruijl TD, Gibbs S. Epidermis-todermis migration of immature Langerhans cells upon topical irritant exposure is dependent on CCL2 and CCL5. Eur J Immunol. 2010;40(7):2026-2034. doi:10.1002/eji.200940150

93. Lee HY, Stieger M, Yawalkar N, Kakeda M. Cytokines and chemokines in irritant contact dermatitis. Mediators Inflamm. 2013;2013:916497. doi:10.1155/2013/916497

94. Van de Kerkhof P, De Hoop D, De Korte J, Cobelens S, Kuipers M. Patient compliance and disease management in the treatment of psoriasis in the Netherlands. Dermatology. 2000;200 (4):292-298. doi:10.1159/000018390

95. Rodgers M, Griffin S, Paulden M, et al. Alitretinoin for severe chronic hand eczema: a NICE single technology appraisal. Pharmacoeconomics. 2010;28(5):351-362. doi:10.2165/11532 160-000000000-00000

96. Politiek K, Christoffers WA, Coenraads PJ, Schuttelaar MA. Alitretinoin and acitretin in severe chronic hand eczema; results from a retrospective daily practice study. Dermatol Ther. 2016;29 (5):364-371. doi:10.1111/dth.12362

97. Shi VY, Sivamani RK, Maibach H. Alitretinoin for the treatment of chronic hand eczema: clinical rationale. Clin Investig (Lond). 2014;4(8):763-773. doi:10.4155/cli.14.58

98. Nada HR, Rashed LA, Elantably DMM, El Sharkawy DA. Expression of retinoid receptors in hand eczema. Int J Dermatol. 2020;59(5):576-581. doi:10.1111/ijd.14830

99. Ruzicka T, Lynde CW, Jemec GB, et al. Efficacy and safety of oral alitretinoin (9-cis retinoic acid) in patients with severe chronic hand eczema refractory to topical corticosteroids: results of a randomized, double-blind, placebo-controlled, multicentre trial. Br J Dermatol. 2008;158(4):808-817. doi:10.1111/j.1365-2133.2008.08487.x

100. Bissonnette R, Worm M, Gerlach B, et al. Successful retreatment with alitretinoin in patients with relapsed chronic hand eczema. Br J Dermatol. 2010;162(2):420-426. doi:10.1111/j.1365-2133. 2009.09572.x
101. Diepgen TL, Pfarr E, Zimmermann T. Efficacy and tolerability of alitretinoin for chronic hand eczema under daily practice conditions: results of the TOCCATA open study comprising 680 patients. Acta Derm Venereol. 2012;92(3):251-255. doi:10.2340/00015555-1256

102. Schindler M, Drozdenko G, Kuhl AA, Worm M. Immunomodulation in patients with chronic hand eczema treated with oral alitretinoin. Int Arch Allergy Immunol. 2014;165 (1):18-26. doi:10.1159/000365659

103. Fowler JF, Graff O, Hamedani AG. A phase 3, randomized, double-blind, placebo-controlled study evaluating the efficacy and safety of alitretinoin (BAL4079) in the treatment of severe chronic hand eczema refractory to potent topical corticosteroid therapy. J Drugs Dermatol. 2014;13(10):1198-1204.

104. Cheng C, Michaels J, Scheinfeld N. Alitretinoin: a comprehensive review. Expert Opin Investig Drugs. 2008;17(3):437-443. doi:10.1517/13543784.17.3.437

105. Blair HA, Scott LJ. Alitretinoin: a review in severe chronic hand eczema. Drugs. 2016;76(13):1271-1279. doi:10.1007/s40265-0160621-0

106. Ingram JR, Batchelor JM, Williams HC. Alitretinoin as a potential advance in the management of severe chronic hand eczema. Arch Dermatol. 2009;145(3):314-315. doi:10.1001/ archdermatol.2008.608

107. Dirschka T, Reich K, Bissonnette R, Maares J, Brown T, Diepgen T. An open-label study assessing the safety and efficacy of alitretinoin in patients with severe chronic hand eczema unresponsive to topical corticosteroids. Clin Exp Dermatol. 2011;36 (2):149-154. doi:10.1111/j.1365-2230.2010.03955.x

108. Gola M, Milanesi N, Derme A. Clinical evaluation and assessment of the therapeutic efficacy of alitretinoin in a group of patients with chronic hand eczema refractory to topical steroid therapy. G Ital Dermatol Venereol. 2014;149(4):435-439.

109. Morris M, Schifano L, Fong R, Graff O. Safety of alitretinoin for severe refractory chronic hand eczema: clinical studies and postmarketing surveillance. J Dermatol Treat. 2016;27(1):54-58. doi:10.3109/09546634.2015.1034080

110. Tan J, Maari C, Nigen S, Bolduc C, Bissonnette R. Open-label exploratory study of acitretin for the treatment of severe chronic hand dermatitis. J Dermatolog Treat. 2015;26(4):373-375. doi:10.3109/09546634.2014.952608

111. Thestrup-Pedersen K, Andersen KE, Menne T, Veien NK. Treatment of hyperkeratotic dermatitis of the palms (eczema keratoticum) with oral acitretin. A single-blind placebo-controlled study. Acta Derm Venereol. 2001;81 (5):353-355. doi:10.1080/000155501317140089

112. Song M, Lee HJ, Lee WK, et al. Acitretin as a therapeutic option for chronic hand eczema. Ann Dermatol. 2017;29(3):385-387. doi:10.5021/ad.2017.29.3.385

113. Pilot study on the use of acitretin for the treatment of severe chronic hand dermatitis. Available from: https://ClinicalTrials. gov/show/NCT01545284. Accessed December 21, 2020.

114. Alitretinoin vs cyclosporine in severe recurrent vesicular hand eczema. Available from: https:/ClinicalTrials.gov/show/ NCT03026946. Accessed December 21, 2020.

115. Alitretinoin vs azathioprine in severe non-hyperkeratotic hand eczema. Available from: https://ClinicalTrials.gov/show/ NCT03026907. Accessed December 21, 2020.

116. Brandt C, Pavlovic V, Radbruch A, Worm M, Baumgrass R. Lowdose cyclosporine A therapy increases the regulatory T cell population in patients with atopic dermatitis. Allergy. 2009;64 (11):1588-1596. doi:10.1111/j.1398-9995.2009.02054.x

117. Khattri S, Shemer A, Rozenblit M, et al. Cyclosporine in patients with atopic dermatitis modulates activated inflammatory pathways and reverses epidermal pathology. J Allergy and Clin Immunol. 2014;133(6):1626-1634. doi:10.1016/j.jaci.2014.03. 003 
118. Schram ME, Roekevisch E, Leeflang MMG, Bos JD, Schmitt J, Spuls PI. A randomized trial of methotrexate versus azathioprine for severe atopic eczema. J Allergy and Clin Immunol. 2011;128 (2):353-359. doi:10.1016/j.jaci.2011.03.024

119. Waxweiler WT, Agans R, Morrell DS. Systemic treatment of pediatric atopic dermatitis with azathioprine and mycophenolate mofetil. Pediatr Dermatol. 2011;28(6):689-694. doi:10.1111/ j.1525-1470.2011.01488.x

120. Caufield M, Tom WL. Oral azathioprine for recalcitrant pediatric atopic dermatitis: clinical response and thiopurine monitoring. J Am Acad Dermatol. 2013;68(1):29-35. doi:10.1016/j.jaad.2012. 07.001

121. Bianchi L, Del Duca E, Romanelli M, Saraceno R, Chimenti S, Chiricozzi A. Pharmacodynamic assessment of apremilast for the treatment of moderate-to-severe plaque psoriasis. Expert Opin Drug Metab Toxicol. 2016;12(9):1121-1128. doi:10.1080/1742 5255.2016.1206886

122. Dattola A, Del Duca E, Saraceno R, Gramiccia T, Bianchi L. Safety evaluation of apremilast for the treatment of psoriasis. Expert Opin Drug Saf. 2017;16(3):381-385. doi:10.1080/147403 38.2017.1288714

123. Zerilli T, Ocheretyaner E. Apremilast (Otezla): a new oral treatment for adults with psoriasis and psoriatic arthritis. Pharm Therap. 2015;40(8):495.

124. Abrouk M, Farahnik B, Zhu TH, et al. Apremilast treatment of atopic dermatitis and other chronic eczematous dermatoses. $J \mathrm{Am}$ Acad Dermatol. 2017;77(1):177-180. doi:10.1016/j.jaad.2017.03. 020

125. Navarro-Trivino FJ, Cuenca-Barrales C, Vega-Castillo JJ, RuizVillaverde R. Chronic hand eczema and hepatogenic pruritus with good response to apremilast. Dermatol Ther. 2019;32(3):e12879. doi: $10.1111 /$ dth. 12879

126. Ghosh N, Nasrin T, Mahmud H, Paul HK. Efficacy and safety of low dose Methotrexate in the treatment of chronic hand eczema. J Pak Assoc Dermatol. 2020;30(1):3-8.

127. Shaffrali FC, Colver GB, Messenger AG, Gawkrodger DJ. Experience with low-dose methotrexate for the treatment of eczema in the elderly. $J$ Am Acad Dermatol. 2003;48 (3):417-419. doi:10.1067/mjd.2003.137

128. Egan CA, Rallis TM, Meadows KP, Krueger GG. Low-dose oral methotrexate treatment for recalcitrant palmoplantar pompholyx. J Am Acad Dermatol. 1999;40(4):612-614. doi:10.1016/S01909622(99)70446-9

129. Apfelbacher CJ, Ofenloch RF, Weisshaar E, et al. Chronic hand eczema in Germany: 5-year follow-up data from the CARPE registry. Contact Dermatitis. 2019;80(1):45-53. doi:10.1111/cod.13113

130. O'Shea PM, Lugo-Somolinos A Methotrexate versus acitretin in the treatment of chronic hand dermatitis. 2015.

131. Politiek K, van der Schaft J, Christoffers WA, et al. Drug survival of methotrexate treatment in hand eczema patients: results from a retrospective daily practice study. J Eur Acad Dermatol Venereol. 2016;30(8):1405-1407. doi:10.1111/jdv.13253

132. Sideris N, Vakirlis E, Tsentemeidou A, Kourouklidou A, Ioannides D, Sotiriou E. Under development JAK inhibitors for dermatologic diseases. Mediterr J Rheumatol. 2020;31(Suppl 1):137-144. doi:10.31138/mjr.31.1.137

133. Szilveszter KP, Németh T, Mócsai A. Tyrosine kinases in autoimmune and inflammatory skin diseases. Front Immunol. 2019;10:1862. doi:10.3389/fimmu.2019.01862

134. He H, Guttman-Yassky E. JAK inhibitors for atopic dermatitis: an update. Am J Clin Dermatol. 2019;20(2):181-192. doi:10.1007/ s40257-018-0413-2

135. Montilla AM, Gómez-García F, Gómez-Arias PJ, et al. Scoping review on the use of drugs targeting JAK/STAT pathway in atopic dermatitis, vitiligo, and alopecia areata. Dermatol Ther (Heidelb). 2019;1-29.
136. Singh R, Heron CE, Ghamrawi RI, Strowd LC, Feldman SR. Emerging role of janus kinase inhibitors for the treatment of atopic dermatitis. ImmunoTargets Ther. 2020;9:255. doi:10.2147/ ITT.S229667

137. Szalus K, Trzeciak M, Nowicki RJJAK-STAT. Inhibitors in atopic dermatitis from pathogenesis to clinical trials results. Microorganisms. 2020;8(11):1743. doi:10.3390/microorganisms 8111743

138. Guttman-Yassky E, Bissonnette R, Ungar B, et al. Dupilumab progressively improves systemic and cutaneous abnormalities in patients with atopic dermatitis. J Allergy Clin Immunol. 2019;143 (1):155-172. doi:10.1016/j.jaci.2018.08.022

139. Hendricks AJ, Yosipovitch G, Shi VY. Dupilumab use in dermatologic conditions beyond atopic dermatitis - a systematic review. $J$ Dermatolog Treat. 2019;1-10.

140. Seegraber M, Srour J, Walter A, Knop M, Wollenberg A. Dupilumab for treatment of atopic dermatitis. Expert Rev Clin Pharmacol. 2018;11(5):467-474. doi:10.1080/17512433.2018. 1449642

141. Soria A, Du-Thanh A, Seneschal J, et al. Development or exacerbation of head and neck dermatitis in patients treated for atopic dermatitis with dupilumab. JAMA Dermatol. 2019;155:1312. doi:10.1001/jamadermatol.2019.2613

142. Lee DE, Clark AK, Tran KA, Shi VY. New and emerging targeted systemic therapies: a new era for atopic dermatitis. J Dermatolog Treat. 2018;29(4):364-374. doi:10.1080/09546634.2017.1373736

143. Kuznik A, Bego-Le-Bagousse G, Eckert L, et al. Economic evaluation of dupilumab for the treatment of moderate-to-severe atopic dermatitis in adults. Dermatol Ther (Heidelb). 2017;7 (4):493-505. doi:10.1007/s13555-017-0201-6

144. Sonya Kahn M, Rind D, Chapman R, Kumar V, Kahn S, Carlson J. Economic evaluation of dupilumab for moderate-tosevere atopic dermatitis: a cost-utility analysis. $J$ Drugs Dermatol. 2018;17(7):750-756.

145. Van Coevorden AM, Coenraads PJ, Svensson A, et al. Overview of studies of treatments for hand eczema-the EDEN hand eczema survey. Br J Dermatol. 2004;151(2):446-451. doi:10.1111/j.13652133.2004.06040.x

146. Veien NK, Olholm Larsen P, Thestrup-Pedersen K, Schou G. Long-term, intermittent treatment of chronic hand eczema with mometasone furoate. $\mathrm{Br} J$ Dermatol. 1999;140(5):882-886. doi:10.1046/j.1365-2133.1999.02819.x

147. Rademaker M, Armour K, Baker C, et al. Management of chronic hand and foot eczema. An Australia/New Zealand Clinical narrative. Australas J Dermatol. 2020. doi:10.1111/ajd.13418

148. LEO 19123 cream in the treatment of hand eczema. Available from: https://ClinicalTrials.gov/show/NCT00404196. Accessed December 21, 2020.

149. A randomised trial of a moisturising cream in preventing recurrence of hand eczema. Available from: https://ClinicalTrials.gov/ show/NCT00576550. Accessed December 21, 2020.

150. Blank PR, Blank AA, Szucs TD. Cost-effectiveness of oral alitretinoin in patients with severe chronic hand eczema-a long-term analysis from a Swiss perspective. BMC Dermatol. 2010;10(1):4. doi:10.1186/1471-5945-10-4

151. King T, McKenna J, Alexandroff AB. Alitretinoin for the treatment of severe chronic hand eczema. Patient Prefer Adherence. 2014;8:1629-1634. doi:10.2147/PPA.S38830

152. Reich A, Wilke A, Gediga G, et al. Health education decreases incidence of hand eczema in metal work apprentices: results of a controlled intervention study. Contact Dermatitis. 2020;82 (6):350-360. doi:10.1111/cod.13502

153. Wang B, Liu -L-L, Zhao Z-T, Tu P. Impaired skin barrier function and downregulated expression of caspase-14 in moderate to severe chronic hand eczema. Dermatology. 2018;234(5-6):180-185. doi:10.1159/000489701 
154. Dyjack N, Goleva E, Rios C, et al. Minimally invasive skin tape strip RNA sequencing identifies novel characteristics of the type 2-high atopic dermatitis disease endotype. J Allergy and Clin Immunol. 2018;141(4):1298-1309. doi:10.1016/j.jaci.2017.10. 046

155. Guttman-Yassky E, Diaz A, Pavel AB, et al. Use of tape strips to detect immune and barrier abnormalities in the skin of children with early-onset atopic dermatitis. JAMA Dermatol. 2019;155 (12):1358-1370. doi:10.1001/jamadermatol.2019.2983
156. He $\mathrm{H}$, Bissonnette $\mathrm{R}, \mathrm{Wu} \mathrm{J}$, et al. Tape strips detect distinct immune and barrier profiles in atopic dermatitis and psoriasis. J Allergy and Clin Immunol. 2020. doi:10.1016/j.jaci.2020.05.048

157. Loesche C, Kolbinger F, Valentin M-A, et al. Interleukin-17A blockade with secukinumab results in decreased neutrophil infiltration in psoriasis: minimally-invasive measurement by tape stripping. Adv Precision Med. 2016;1:1-9. doi:10.18063/ APM.2016.02.003

\section{Publish your work in this journal}

Therapeutics and Clinical Risk Management is an international, peerreviewed journal of clinical therapeutics and risk management, focusing on concise rapid reporting of clinical studies in all therapeutic areas, outcomes, safety, and programs for the effective, safe, and sustained use of medicines. This journal is indexed on PubMed Central, CAS,
EMBase, Scopus and the Elsevier Bibliographic databases. The manuscript management system is completely online and includes a very quick and fair peer-review system, which is all easy to use. Visit http://www.dovepress.com/testimonials.php to read real quotes from published authors. 